\title{
Laser assisted plasma spectrochemistry: laser ablation $\uparrow$
}

\author{
R. E. Russo,* X. L. Mao, C. Liu and J. Gonzalez \\ Lawrence Berkeley National Laboratory, 1 Cyclotron Road, Mail Stop 70-108B, \\ Berkeley, CA, USA. E-mail: rerusso@lbl.gov
}

Received 4th March 2004, Accepted 27th May 2004

First published as an Advance Article on the web 16th August 2004

This paper presents a brief overview of the current research issues in laser ablation for chemical analysis, discusses several fundamental studies of laser ablation using time-resolved shadowgraph and spectroscopic imaging, and describes recent data using femtosecond ablation sampling for ICP-MS and LIBS. This manuscript represents a summary of the plenary lecture presented at the 2004 Winter Conference on Plasma Spectrochemistry.

\section{Introduction-overview}

Laser ablation is becoming the leading technology for direct solid sample chemical analysis. The 2004 Winter Plasma Conference on Plasma Spectrochemistry included dedicated sessions to laser ablation, as well as a significant number of poster contributions. Laser ablation is one of the few technologies that operates at atmospheric pressure and can be used to analyze any sample. Without the need for complicated acid digestion, laser ablation is easier, less expensive and safer than conventional liquid nebulization. Laser ablation can provide rapid chemical analysis either in the laboratory or in the field.

In our world, laser ablation refers to sampling for chemical analysis. However, a search of Current Contents using the key phrase 'laser ablation' provides approximately 1000 hits for each year over the past ten years. Only about $10 \%$ of these papers are related to chemical analysis. Laser ablation is used by the materials community for fabricating thin films, including semiconductor, superconductor, and giant magneto-resistive materials. Another area of laser ablation is the fabrication of nanomaterials. Other studies and applications of laser ablation can be found in medicine, micromachining, military, and X-ray lasers.

The analytical community is actively studying the parameters (laser, sample and detector) influencing analytical performance. ${ }^{1-10}$ Many of these current issues were addressed when laser ablation initially was studied in the early 1980s for chemical analysis. There was a tremendous body of literature on laser ablation using other excitation sources before ICP-MS. High-voltage sparks, ${ }^{11}$ microwave plasmas, ${ }^{12}$ direct current plasmas, ${ }^{13}$ graphite furnaces ${ }^{14}$ and ICP-AES have been used as excitation sources with laser ablation. ${ }^{15-24}$ Today, the two prevalent laser ablation technologies for solid sampling are inductively coupled plasma mass spectrometry (LA-ICP-MS) and laser-induced breakdown spectrometry (LIBS). For both these technologies, a focused laser beam converts a tiny portion of a solid sample into a vaporphase aerosol. For ICP-MS, the ideal aerosol would be comprised of small uniform-sized particles that could be entrained and transported efficiently to the ICP. For LIBS, the ideal vapor would be spectrally excited atomic and ionic species. Fundamentally, both vapor forms could be produced, and are established by the experimental parameters. The ideal parameters for LIBS may not be ideal for ICP-MS.

$\uparrow$ Presented at the 2004 Winter Conference on Plasma Spectrochemistry, Fort Lauderdale, FL, USA, January 5-10, 2004.
The properties of the laser beam that influence ablation are pulse duration, energy, wavelength, and spatial energy profile. The irradiance (energy per unit time and area) plays the dominant role in defining the quantity and chemistry (fractionation) of the ablated aerosol. The research studying laser properties is based on the need to ablate samples without matrix dependence and without fractionation (ablated mass vapor is not chemically equal to the original sample). ${ }^{8-10,25-30}$ Understanding and eliminating elemental fractionation has been one of the most significant research agendas in laser ablation sampling. ${ }^{31-40}$ It is important to point out that the occurrence of fractionation does not preclude the use of laserablation sampling for accurate chemical analysis: numerous successful applications have been demonstrated. ${ }^{41-50}$ Fractionation is a function of laser beam properties (irradiance, pulse duration, wavelength). The wavelength effect on fractionation is of great interest. ${ }^{33,34,37,40,51-53}$ In general, shorter wavelengths reduce fractionation. However, fractionation can be increased or reduced using all wavelengths if the respective lasers have enough variability of parameters (energy, irradiance). Fractionation can be described in two ways, non-stoichiometric ablation from a single laser pulse, or the time dependent change in elemental ratio as a crater is formed during repetitive laser pulsing at one sample location. Fractionation is not due to laser ablation alone, as fractionation can and does occur during transport and in the ICP-MS. ${ }^{54-56}$

Ablation does not necessarily produce the same amount of mass from each laser pulse, and the particle size distribution can change from pulse to pulse. Each of these effects will influence precision. We define two types of precision using laser ablation, internal and external. Internal precision is defined as the reproducibility of ablating and analyzing a homogeneous sample, using a repetitive pulsed laser at a fixed position. External precision is defined as the reproducibility of ablating different locations on a sample. As a correlation to liquid sample introduction, internal precision would be related to nebulization stability of a given solution. External stability would be related to nebulization of several similar solutions.

Commercial laser ablation systems for chemical analysis utilize nanosecond-pulsed Nd:YAG or excimer lasers, although a current research trend is the investigation of picosecond and femtosecond pulses. ${ }^{57-62}$ In general, greater ablation efficiency (amount of mass removed per unit energy), reduced plasma shielding, and reduced fractionation are realized by using short laser wavelengths (UV) and short laser-pulse durations. For picosecond and femtosecond lasers, the pulse duration can be comparable to or shorter than the phonon 
relaxation time, i.e., the laser energy can be deposited into the material before it can thermally equilibrate. Ideally, this type of interaction will lead to more of a photo-physical bond breaking process instead of classical melting, boiling, and vaporization. A goal of using short laser pulses is to ablate the entire optical and heat-affected volumes so that elemental migration and fractionation are negligible. In addition, the short pulse regime may be less susceptible to the material's properties, thereby providing matrix-independent sampling.

\section{Fundamental studies using imaging}

The graph in Fig. 1 demonstrates the non-linearity of ablation based on laser irradiance, with two measurement examples. ${ }^{63,64}$ The slopes and inflection points in the graph

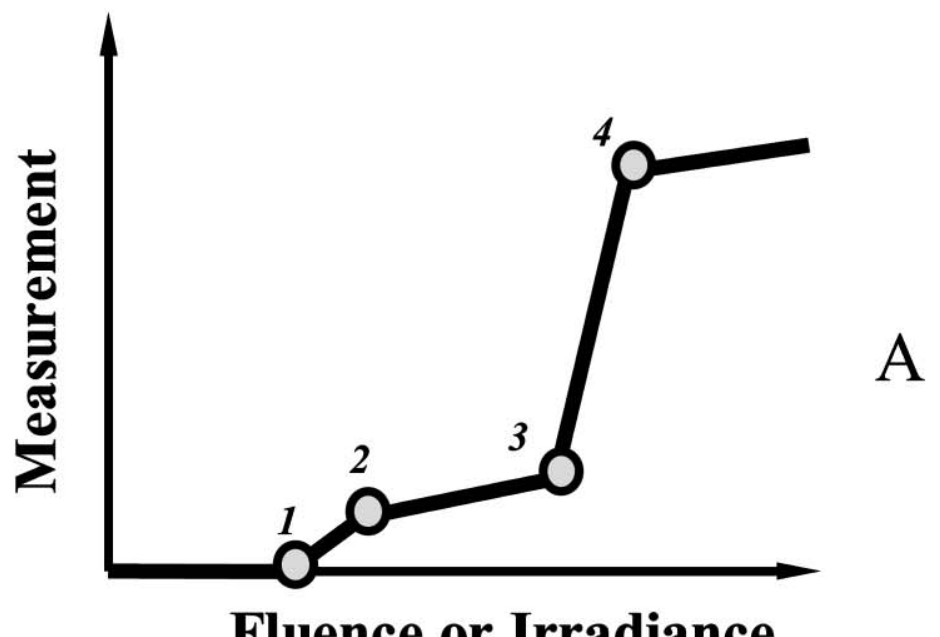

Nd: YAG Laser, $\lambda=266 n m, t_{p}=3 n s, t_{d}=30 n s, t_{g}=20 n s$
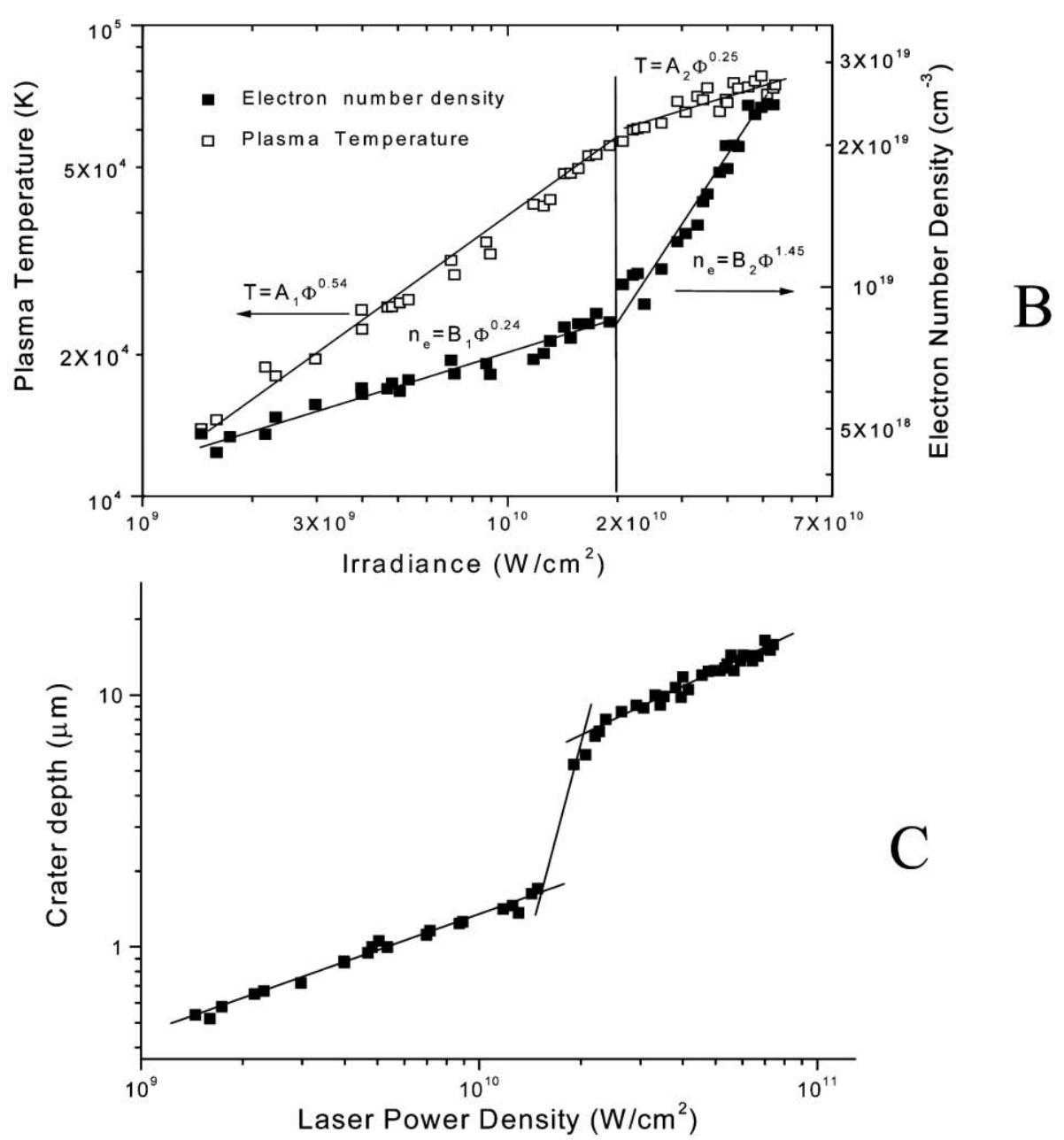

Fig. 1 A, Representation of non-linear laser ablation behaviour as a function of the laser beam fluence/irradiance. ${ }^{63}$ B, Measurements of laserinduced plasma temperature and electron number density. ${ }^{64} \mathrm{C}$, Measurement of the crater depth (log scale). ${ }^{64}$ 
depend on the laser and sample properties. Non-linear behaviour has been measured for plasma temperature, ICP-MS intensity, shockwave energy in the sample and plume, and crater volumes. Such non-linear behaviours have been known since the 1960 s. $^{24,63,65,66}$ Different mechanisms have been proposed to describe ablation in each of these regions. For example, region 1 may be dominated by thermal effects, region 2 by plasma absorption, region 3 by phase explosion, and region 4 by high energy plasma. ${ }^{67-70}$ The mass ablation rate, plasma temperature, particle size distribution, and particle chemistry will be different in each of these regions. It is well know that the laser-beam wavelength influences the ablation process. . $^{33,34,37,40,51-53,71}$ However, ablation depends significantly on the irradiance, not just wavelength. Similarly, the gas ambient may or may not influence ablation; an enhancement or depression may be measured depending on the irradiance. ${ }^{67,68,72-75}$ Probably the biggest emphasis today is the particle size distribution. The number of particles and their size distribution also depends on the laser irradiance, as well as wavelength, fluence, ambient gas and pressure, and properties of the sample. ${ }^{24,31,35,36,55,67-69,76-78}$
The particle influence on fractionation and analytical performance is a critical area that needs to be thoroughly investigated.

Fig. 2 shows an experimental system for studying (nonlinear) fundamental laser ablation processes. Depending on the lasers and configuration, femtosecond time resolution imaging of the 'plume' in (transparent sample only) or above a sample surface is possible. ${ }^{79}$ One laser beam is used to ablate the sample (target) and a second beam is used as a time-resolved probe to image events during/after the ablation process. As configured, the system also forms an interferometer at the sample, providing the capability for determining the number density of species in the plume. ${ }^{80}$ Fig. 3 shows images of shockwaves and particles measured using the system in Fig. $2{ }^{81}$ Each of the images represents the sample surface (bottom dark portion) and the ambient approximately 500 microns above. This example shows shockwave propagation in time as well as the release of particles after a few hundred nanoseconds. However, large particles are only observed in Fig. 3b, when the irradiance is above a certain threshold (for example, threshold 3 in Fig. 1). ${ }^{81}$ Time-resolved imaging

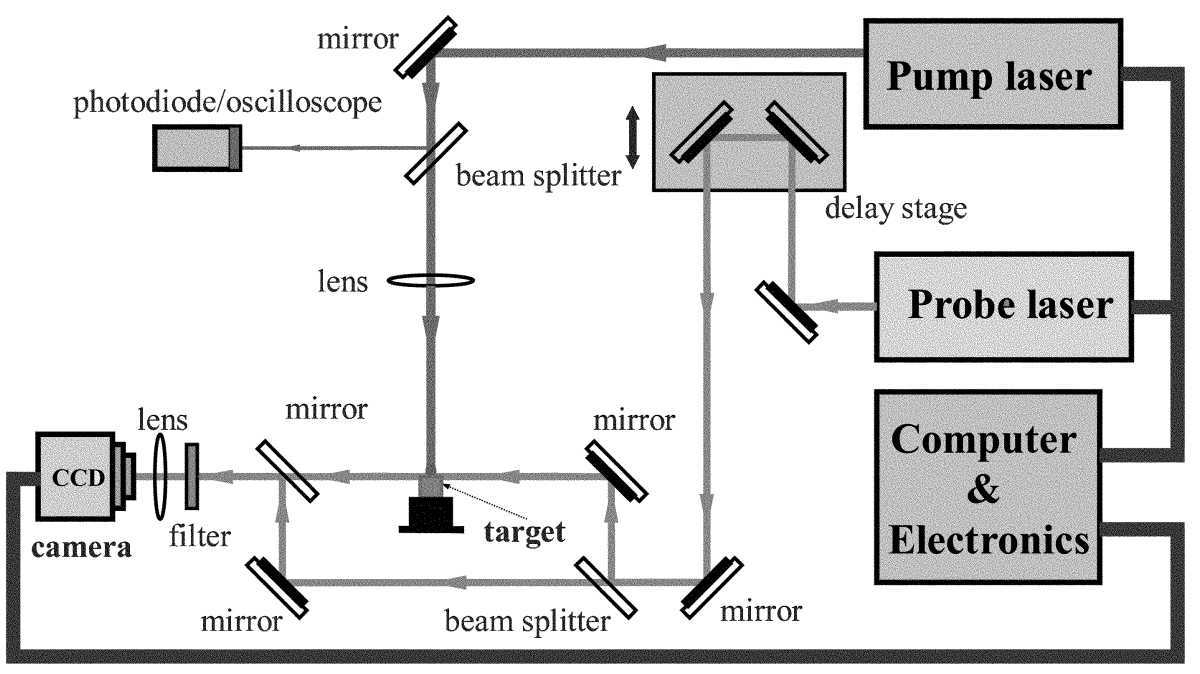

Fig. 2 Pump-probe imaging system for measuring time-resolved laser ablation processes.

a
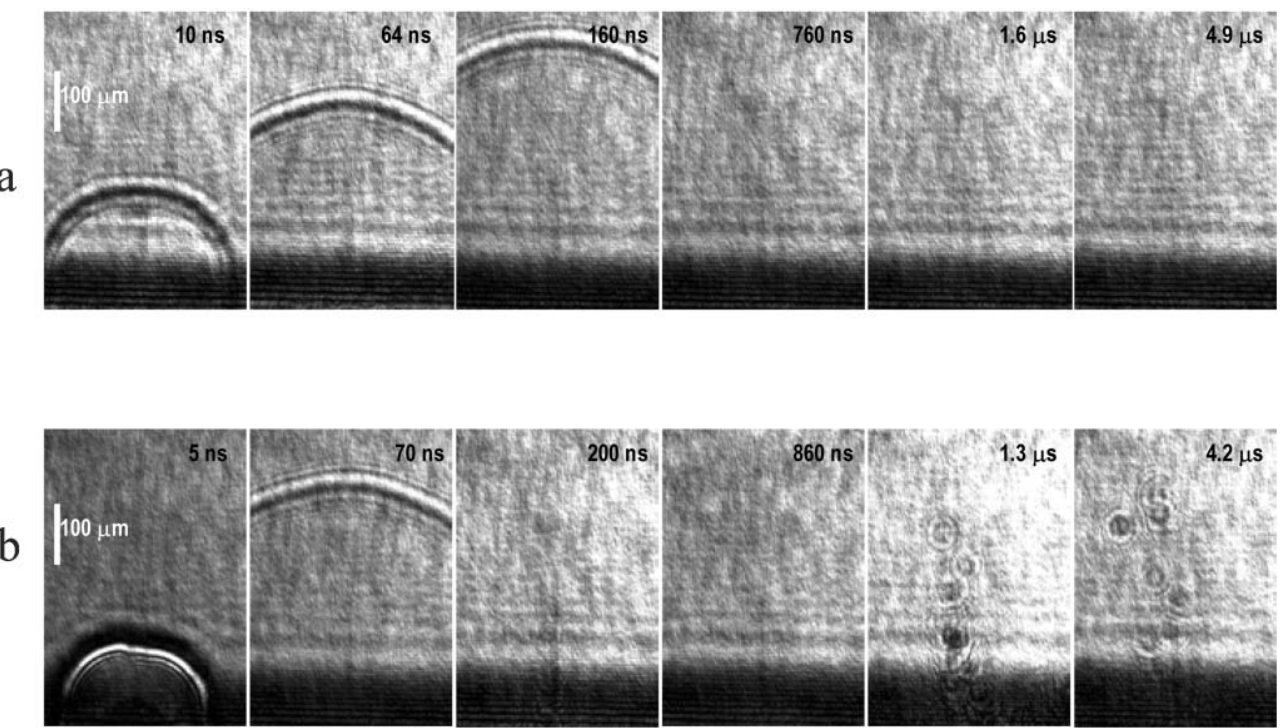

Fig. 3 Time-resolved shadowgraph images of the ambient in front of the sample after laser ablation. Laser is from the top with the sample at the bottom. ${ }^{81}$ a, Below the threshold for phase explosion $\left(1.9 \mathrm{GW} \mathrm{cm}^{-2}\right)$. b. Above the phase explosion threshold $\left(2.1 \mathrm{GW} \mathrm{cm}^{-2}\right)$. 
systems have provided fundamental studies of electrons, atomic/ionic mass and particles for various samples and lasers.

\section{Femtosecond versus nanosecond ablation}

There are compelling reasons to delve into the ultrafast regime for ablation-differences in the laser-sample and the laserplasma interactions. Ultrafast (femtosecond) lasers offer very high photon intensities $\left(>10^{15} \mathrm{~W} \mathrm{~cm}^{-2}\right)$ with a pulse duration (femtoseconds) shorter than many fundamental time scales (phonon vibrations). Laser ablation on the femtosecond time scale is predominantly non-thermal, offering the potential to eliminate fractionation and matrix dependence. Femtosecond ablation provides less sample heating, no laser-plasma interaction and smaller aerosol particle sizes. ${ }^{82}$ Comparative LIBS and ICP-MS studies using femtosecond and nanosecond lasers were performed using samples of NIST glasses, geological materials and alloys. ${ }^{83}$ For these comparison studies, the laser energy per pulse and focused spot size on the sample surface were the same: the laser irradiance was the only difference. The data in Figs. 4 and 5 show the improvements in the ICP-MS analysis of brass alloys and NIST silicate glasses. Significant improvements in analytical performance can be seen. Precision and accuracy were improved by using femtosecond laser ablation for both classes of samples. For the brass alloy, the spikes due to larger particles were almost completely eliminated. Internal and external precision were improved using repetitive pulsed femtosecond laser ablation. ${ }^{83}$

The analytical capabilities of LIBS are determined by the plasma properties, which depend on experimental parameters, including the laser pulse (energy, duration, repetition rate and wavelength), the sample (physical and optical), and ambient atmosphere (gas, pressure). Several studies have explored the use of ultrashort ( $\mathrm{ps}$ and fs) pulsed lasers for LIBS. ${ }^{62,84-88}$ The spatial extent, growth and decay of ionic and atomic emission lines were significantly different for femtosecond LIBS. Plasma temperature and electron number density are shown for femtosecond and nanosecond pulsed LIBS (Fig. 6). ${ }^{89}$ The emission lifetime of spectral
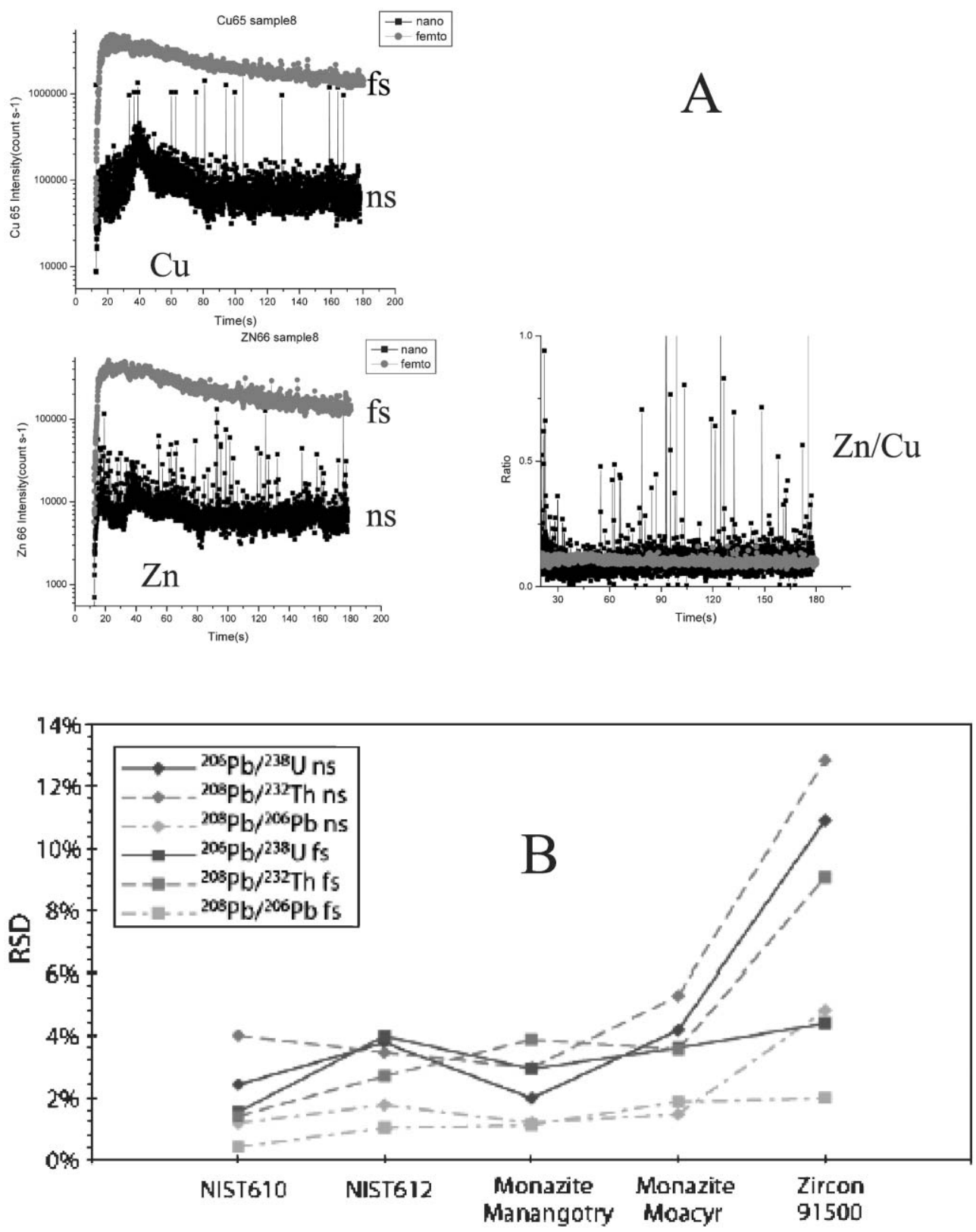

Fig. 4 ICP-MS behaviour for nanosecond and femtosecond ablation. $\mathrm{A}, \mathrm{Zn}, \mathrm{Cu}$, and $\mathrm{Zn} / \mathrm{Cu}$ ratio as a function of time. ${ }^{82} \mathrm{~B}$, Isotopic and elemental precision for silicate glasses and geological samples. ${ }^{83}$ 


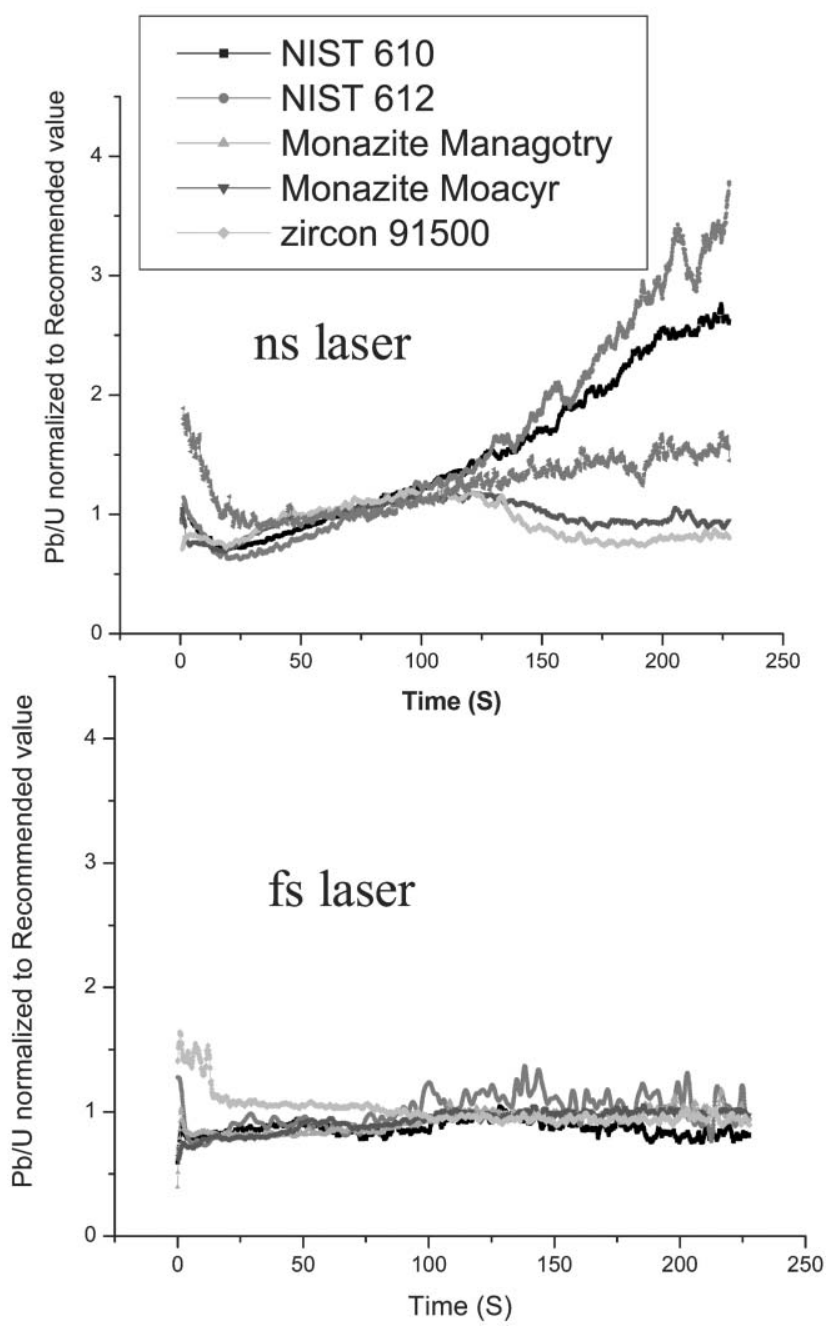

Fig. $5 \mathrm{~Pb} / \mathrm{U}$ accuracy for samples in Fig. 4B. ${ }^{83}$

lines was at least an order of magnitude shorter and the continuum background was significantly lower than that from nanosecond induced plasmas. The femtosecond-induced plasma was cooler and expanded more rapidly because it was not influenced by absorption of the laser beam.

\section{Conclusion}

Laser ablation for chemical analysis is currently the leading technology for direct solid sampling at atmospheric pressure. The fundamental issues may seem ominous, but they do not preclude the application of laser ablation. There have been tremendous advancements in laser ablation sampling for chemical analysis. Current studies are concentrating on particles, with emphasis on laser ablation, transport, and ICP-MS behaviour. Femtosecond laser pulses are showing promise in achieving matrix independence and the elimination of fractionation.

Most results in the literature are based on a particular instrument; it is a risk to make broad general claims about the fundamental mechanisms responsible for specific data. New studies based on modelling are needed to better define and predict the ablation process. ${ }^{90}$ Decades of research have been required to develop nebulizers and sample introduction systems, in addition to the chemistry required for acid dissolution of solid samples. Laser ablation is a simpler and safer technology.
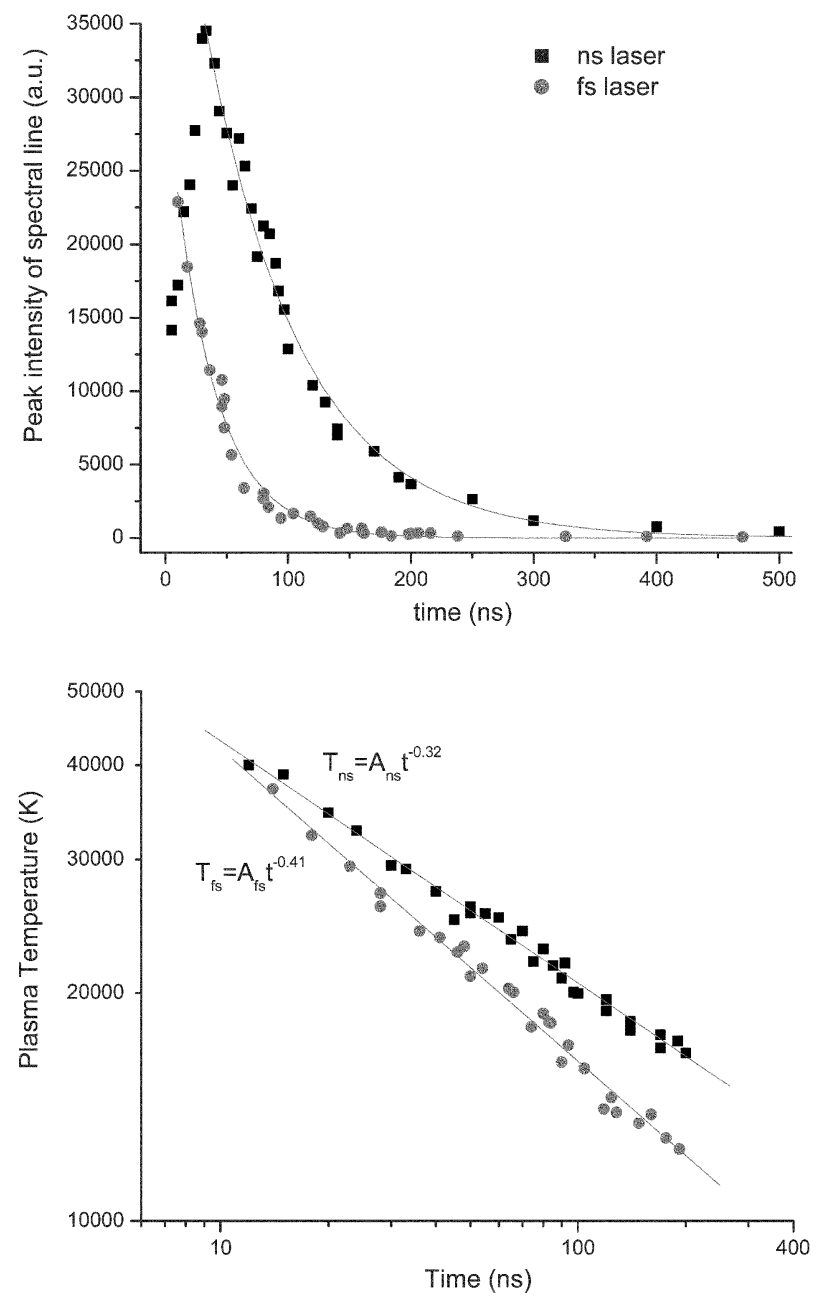

Fig. 6 Laser induced plasma intensity ( $\mathrm{Si}$ ) and temperature for nanosecond and femtosecond ablation of silicon sample. ${ }^{89}$

\section{Acknowledgements}

Supported by the U.S. Department of Energy, Office of Nuclear Non-Proliferation and Office of Basic Energy Sciences, Chemical Sciences Division, under Contract No. DE-AC03-76SF00098 at the Lawrence Berkeley National Laboratory.

\section{References}

D. B. Aeschliman, S. J. Bajic, D. P. Baldwin and R. S. Houk, J. Anal. At. Spectrom., 2003, 18, 872-877.

2 M. Balcerzak, Anal. Sci., 2003, 19, 979-989.

3 D. Bleiner, P. Lienemann, A. Ulrich, H. Vonmont and A. Wichser, J. Anal. At. Spectrom., 2003, 18, 1146-1153.

4 G. C. Y. Chan and W. T. Chan, Spectrochim. Acta, Part B, 2003, 58, 1301-1317.

5 I. Horn, M. Guillong and D. Gunther, Appl. Surf. Sci., 2001, 182, 91-102.

6 V. Kanicky, V. Otruba and J. M. Mermet, Spectrochim. Acta, Part $B, 2000$, 55, 575-586.

7 M. P. Mateo, L. M. Cabalin and J. Laserna, Appl. Optics, 2003, 42 , 6057-6062.

8 K. Niemax, Fresenius' J. Anal. Chem., 2001, 370, 332-340.

9 I. Rodushkin, M. D. Axelsson, D. Malinovsky and D. C. Baxter, J. Anal. At. Spectrom., 2002, 17, 1223-1230.

10 J. D. Winefordner, I. B. Gornushkin, D. Pappas, O. I. Matveev and B. W. Smith, J. Anal. At. Spectrom., 2000, 15, 1161-1189.

11 R. Wennrich, K. Dittrich and U. Bonitz, Spectrochim. Acta, Part B, 1984, 39, 657-666.

12 A. Ciocan, L. Hiddemann, J. Uebbing and K. Niemax, J. Anal. At. Spectrom., 1993, 8, 273-278. 
13 P. G. Mitchell, J. Sneddon and L. J. Radziemski, Appl. Spectrosc., 1987, 41, 141-148.

14 R. Wennrich and K. Dittrich, Spectrochim. Acta, Part B, 1982, 37, 913-919.

15 P. Arrowsmith, Anal. Chem., 1987, 59, 1437-1444.

16 J. W. Carr and G. Horlick, Spectrochim. Acta, Part B, 1982, 37, $1-15$.

17 N. Furuta, Appl. Spectrosc., 1991, 45, 1372-1376.

18 A. L. Gray, Analyst, 1985, 110, 551-556.

19 Z. W. Hwang, Y. Y. Teng, K. P. Li and J. Sneddon, Appl. Spectrosc., 1991, 45, 435-441.

20 T. Ishizuka and Y. Uwamino, Spectrochim. Acta, Part B, 1983, 38, $519-527$

21 K. Laqua, Anal. Laser Spectrosc., 1979.

22 R. M. Measures and H. S. Kwong, Appl. Optics, 1979, 18, 281-286

23 L. Moenke Blankenburg, T. Schumann, D. Gunther, H. M. Kuss and M. Paul, J. Anal. At. Spectrom., 1992, 7, 251-254.

24 W. T. Chan and R. E. Russo, Spectrochim. Acta, Part B, 1991, 46, 1471-1486.

25 J. S. Becker, J. Anal. At. Spectrom., 2002, 17, 1172-1185.

26 S. F. Durrant, J. Anal. At. Spectrom., 1999, 14, 1385-1403.

27 S. M. Eggins, L. P. J. Kinsley and J. M. G. Shelley, Appl. Surf. Sci., 1998, 129, 278-286

28 H. F. Falk, B. Hattendorf, K. Krengel-Rothensee, N. Wieberneit and S. L. Dannen, Fresenius' J. Anal. Chem., 1998, 362, 468-472.

29 D. Gunther, I. Horn and B. Hattendorf, Fresenius' J. Anal. Chem., $2000,368,4-14$.

30 R. E. Russo, X. L. Mao, H. C. Liu, J. Gonzalez and S. S. Mao, Talanta, 2002, 57, 425-451.

31 J. E. Carranza and D. W. Hahn, Anal. Chem., 2002, 74, 5450-5454.

32 D. Figg and M. S. Kahr, Appl. Spectrosc., 1997, 51, 1185-1192.

33 J. Gonzalez, X. L. Mao, J. Roy, S. S. Mao and R. E. Russo, J. Anal. At. Spectrom., 2002, 17, 1108-1113.

34 M. Guillong, I. Horn and D. Gunther, J. Anal. At. Spectrom., 2003, 18, 1224-1230.

35 M. Guillong and D. Gunther, J. Anal. At. Spectrom., 2002, 17, 831-837.

36 R. Jaworski, E. Hoffmann and H. Stephanowitz, Int. J. Mass Spectrom., 2002, 219, 373-379.

37 T. E. Jeffries, S. E. Jackson and H. P. Longerich, J. Anal. At. Spectrom., 1998, 13, 935-940.

38 X. L. Mao, A. C. Ciocan and R. E. Russo, Appl. Spectrosc., 1998, 52, 913-918

39 P. M. Outridge, W. Doherty and D. C. Gregoire, Spectrochim. Acta, Part B, 1997, 52, 2093-2102.

40 R. E. Russo, X. L. Mao, O. V. Borisov and H. C. Liu, J. Anal. At. Spectrom., 2000, 15, 1115-1120.

41 R. A. Cox, D. H. C. Wilton and J. Kosler, Can. Mineral., 2003, 41, 273-291.

42 S. S. Dimov, S. L. Chryssoulis and R. H. Lipson, Anal. Chem., 2003, 75, 6723-6727.

43 S. M. Eggins, Geostand. Newsl. J. Geostand. Geoanal., 2003, 27, $147-162$.

44 B. M. Gillanders and M. J. Kingsford, Estuarine Coast. Shelf Sci., 2003, 57, 1049-1064.

45 A. L. Hobbs and J. R. Almirall, Anal. Bioanal. Chem., 2003, 376, $1265-1271$.

46 K. Kyser, D. Chipley, A. Bukata, P. P. Polito, A. Fitzpatrick and Alexandre, Can. J. Anal. Sci. Spectrosc., 2003, 48, 258-268.

47 M. Ponting, J. A. Evans and V. Pashley, Archaeometry, 2003, 45, 591-597.

48 M. Resano, F. Vanhaecke, D. Hutsebaut, K. De Corte and L. Moens, J. Anal. At. Spectrom., 2003, 18, 1238-1242.

49 T. Trejos, S. Montero and J. R. Almirall, Anal. Bioanal. Chem., 2003, 376, 1255-1264.

50 T. Uryu, J. Yoshinaga, Y. Yanagisawa, M. Endo and J. Takahashi, Anal. Sci., 2003, 19, 1413-1416.

51 R. Fabbro, E. Fabre, F. Amiranoff, C. Garbanlabaune, J. Virmont, M. Weinfeld and C. E. Max, Phys. Rev. A, 1982, 26, 2289-2292.

52 D. Gunther and C. A. Heinrich, J. Anal. At. Spectrom., 1999, 14, $1369-1374$

53 K. Watanabe, K. Hattori, J. Kawarabayashi and T. Iguchi, Spectrochim. Acta, Part B, 2003, 58, 1163-1169.

54 T. Hirata, Y. Hayano and T. Ohno, J. Anal. At. Spectrom., 2003, 18, $1283-1288$.
55 J. Koch, I. Feldmann, N. Jakubowski and K. Niemax, Spectrochim. Acta, Part B, 2002, 57, 975-985.

56 B. Kozlov, A. Saint and A. Skroce, J. Anal. At. Spectrom., 2003, 18, 1069-1075

57 A. Cavalleri, K. Sokolowski-Tinten, J. Bialkowski and D. der Linde, Appl. Phys. Lett., 1998, 72, 2385-2387.

58 M. K. Kim, T. Takao, Y. Oki and M. Maeda, Jpn. J. Appl. Phys., Part 1-Reg. Pap. Short Notes Rev. Pap., 2000, 39, 6277-6280.

59 V. Margetic, M. Bolshov, A. Stockhaus, K. Niemax and R. Hergenroder, J. Anal. At. Spectrom., 2001, 16, 616-621.

60 R. E. Russo, X. L. Mao, J. J. Gonzalez and S. S. Mao, J. Anal. At. Spectrom., 2002, 17, 1072-1075.

61 A. Semerok, C. Chaleard, V. Detalle, J. L. Lacour, P. Mauchien, P. Meynadier, C. Nouvellon, B. Salle, P. Palianov, M. Perdrix and G. Petite, Appl. Surf. Sci., 1999, 139, 311-314.

62 A. Semerok, B. Salle, J. F. Wagner and G. Petite, Laser Particle Beams, 2002, 20, 67-72.

63 R. E. Russo, X. L. Mao and S. S. Mao, Anal. Chem., 2002, 74, $70 \mathrm{~A}-77 \mathrm{~A}$.

64 H. C. Liu, X. L. Mao, J. H. Yoo and R. E. Russo, Spectrochim. Acta, Part B, 1999, 54, 1607-1624.

65 C. R. Phipps and R. W. Dreyfus, in Laser Ionization Mass Analysis, eds. R.Vertes, R.Gijbels and F.Adams, John Wiley \& Son, New York, 1993.

66 Y. B. Zel'dovich and Y. P. Raizer, Physics of Shock Waves and High Temperature Hydrodynamic Phenomena, Academic Press, New York, 1966.

67 N. Bloembergen, in Laser Solid Interaction and Laser Processing, American Institute of Physics, New York, 1979.

68 J. F. Ready, Effect of High-Power Laser Radiation, Academic Press, New York, 1971

69 M. Von Allmen, in Laser-Beam Interactions with MaterialsPhysical Principles and Applications, Springer-Verlag, New York, 1987.

70 G. M. Weyl, in Laser-Induced Plasmas and Applications, eds. L.J. Radziemski and D.A.Cremers, Dekker, New York, 1989.

71 W. T. Chan, X. L. Mao and R. E. Russo, Appl. Spectrosc., 1992, 46, 1025-1031.

72 S. F. Durrant, Fresenius' J. Anal. Chem., 1994, 349, 768-771.

73 Y. Iida, Spectrochim. Acta, Part B, 1990, 45, 1353-1367.

74 A. L. Lewis and E. H. Piepmeier, Appl. Spectrosc., 1983, 37, 523-530.

75 R. E. Russo, X. L. L. Mao, M. Caetano and M. A. Shannon, Appl. Surf. Sci., 1996, 96-8, 144-148.

76 D. B. Aeschliman, S. J. Bajic, D. P. Baldwin and R. S. Houk, J. Anal. At. Spectrom., 2003, 18, 1008-1014.

77 S. H. Jeong, O. V. Borisov, J. H. Yoo, X. L. Mao and R. E. Russo, Anal. Chem., 1999, 71, 5123-5130.

78 M. Thompson, S. Chenery and L. Brett, J. Anal. At. Spectrom., 1990, 5, 49.

79 X. L. Mao, S. S. Mao and R. E. Russo, Appl. Phys. Lett., 2003, 82, 697-699.

80 S. S. Mao, X. Mao, R. Greif and R. E. Russo, Appl. Phys. Lett., 2000, 77, 2464-2466.

81 J. H. Yoo, S. H. Jeong, R. Greif and R. E. Russo, J. Appl. Phys., $2000,88,1638-1649$.

82 C. Liu, X. L. Mao, S. S. Mao, X. Zeng, R. Greif and R. E. Russo, Anal. Chem., 2004, 76, 379-383.

83 F. Poitrasson, X. L. Mao, S. S. Mao, R. Freydier and R. E. Russo, Anal. Chem., 2003, 75, 6184-6190.

84 S. M. Angel, D. N. Stratis, K. L. Eland, T. S. Lai, M. A. Berg and D. M. Gold, Fresenius' J. Anal. Chem., 2001, 369, 320-327.

85 K. L. Eland, D. N. Stratis, D. M. Gold, S. R. Goode and S. M. Angel, Appl. Spectrosc., 2001, 55, 286-291.

86 B. Le Drogoff, J. Margot, M. Chaker, M. Sabsabi, O. Barthelemy, T. W. Johnston, S. Laville, F. Vidal and Y. von Kaenel, Spectrochim. Acta, Part B, 2001, 56, 987-1002.

87 V. Margetic, A. Pakulev, A. Stockhaus, M. Bolshov, K. Niemax and R. Hergenroder, Spectrochim. Acta, Part B, 2000, 55, 1771-1785.

88 V. Margetic, K. Niemax and R. Hergenroder, Spectrochim. Acta, Part B, 2001, 56, 1003-1010.

89 X. Zeng, X. L. Mao, R. Greif and R. E. Russo, Appl. Physics A, 2004, submitted for publication.

90 A. Bogaerts, Z. Y. Chen, R. Gijbels and A. Vertes, Spectrochim. Acta, Part B, 2003, 58, 1867-1893. 